\title{
Unsustainable pace
}

\author{
The delayed Tokyo Olympics were promised to be an example of how to stage an ecologically and socially \\ responsible mega-event, but historical evidence and current trends suggest this may not be possible.
}

n

n 1894, the Baron Pierre de Coubertin, a

French aristocrat who was obsessed with the ancient Olympic Games, helped to form the International Olympic Committee (IOC), whose mission was to organize and stage a revival of the event that had been held every four years for a millennium in the same site in Olympia, Greece. The first iteration of the modern Games was held in nearby Athens in 1896, where a gleaming marble stadium that already existed would host four out of the nine sports on the programme. Even accounting for all of the travel involved in what was (at that time) the largest international sporting event ever held, it is possible that, due to the small size and judicious use of venues, this was the most sustainable Olympics in modern times.

Somebody as ambitious and idealistic as the Baron Coubertin could not have imagined that the Olympics would, despite cancellations and boycotts, become the global juggernaut that exists today - a massive financial and political organization that transforms and shapes cities and athletics worldwide. The Summer Games routinely feature over 10,000 athletes in over two dozen sports, and are held in some of the largest cities around the world. The Winter Games, while smaller at under 4,000 athletes, have outgrown mountain villages and ski resorts and now have to be centred in major cities. The 2022 and 2026 Games will be held in Beijing, China and Milan, Italy, respectively, but the skiing and sledding events will all be held hundreds of kilometres away in both instances.

However, the advertising influence, financial power and political clout wielded by the Olympics has begun to crack in recent years, as various corruption scandals and persistent deficits for host cities have eroded public trust in wanting to stage future editions. Behind the economic toll, but increasingly visible in a world more attuned to climate change and carbon emissions, is the growing awareness of whether the Olympics and other sporting mega-events can justify themselves in ecological terms.
The 2014 Winter Games in Sochi, Russia, were marked by unprecedentedly high temperatures which led to cross-country skiing in $14{ }^{\circ} \mathrm{C}$ weather, and as ski resorts around the world are witnessing reduced snowfall endangering their operations, research suggests that by the end of the century most of the cities that have hosted the Winter Olympics may be too warm to host them again. Similarly, the Summer Olympics will experience this warming trend to such an extent that most Northern Hemisphere cities may be too hot to reasonably host the Games by the end of the century. At the Tokyo Games this summer, the marathon, typically designed so that the finish line is in the main Olympic stadium, will instead take place 500 miles to the north to prevent the expected sweltering temperatures and humidity in the host city from endangering the runners.

In this issue of Nature Sustainability, a collection of pieces puts the Olympics in focus. An Analysis from Martin Müller and his colleagues at the University of Lausanne examines the sustainability of this global mega-event by developing an index to quantify the economic, social and environmental sustainability of each edition of the Summer and Winter Games since 1992. They found that the Olympics have become less sustainable over time, with Salt Lake 2002 and Barcelona 1992 serving as the most sustainable Winter and Summer Games, respectively, while Sochi 2014 and Rio 2016 were the worst-performing events. They estimate that the Tokyo Games will fall, at best, into the middle of the pack due to the massive budget overruns that were happening even before the pandemic delays.

This unsustainable trend has not gone unnoticed by grassroots groups who have been trying to prevent or reform the Olympics being held in their cities, as Jules Boykoff writes in an accompanying News \& Views. He also points out that the IOC has allowed organizers to stage events and force athletes into compromised venues at previous Olympics, such as rowing in the polluted Guanabara Bay in Rio de Janeiro in 2016. This summer, some baseball and softball games will be played in Fukushima, the site of continued decontamination efforts following the nuclear plant disaster of 2010.

Finally, in a Comment, John and Margaret Gold discuss sustainability in the context of the Games' 'legacy' and the IOC's efforts to change itself going forward. The Golds highlight how the concept of sustainability, while routinely touted as a priority for host cities, was still very permissive in the hands of Olympic organizers who wanted to promote the economic revitalization potential of the Games, yet unwittingly added to the mounting evidence that they may not be worth the expense.

All of this is not to say that the Olympics are doomed, but that the recent form of soliciting expensive, overly optimistic bids from numerous cities (many of whom had never hosted an event of this kind before) was a pace that could not be sustained for long - much like a long-distance runner starting their final sprint with a thousand metres left to the finish line, rather than a hundred. Müller et al. recommend some changes to improve the sustainability of the Olympics, including a lasting shift away from in-person spectators along with a more concrete commitment from the IOC to sustainability policies and monitoring.

Their second recommendation, that the Olympics be rotated around a permanent set of host cities, has been proposed for some time now and may end up being the best way forward. Having a few cities serve as permanent sites for both the Winter and Summer Games, with fixed infrastructure and venues reused for decades, is likely the only way to make the Olympics sustainable in the long term. It would also be a return to the ways of the ancient Olympians; after all, a thousand years is quite the world record to beat.

Published online: 20 April 2021 https://doi.org/10.1038/s41893-021-00716-4 